\title{
Abordagens cognitivas para a identificação de unidades geomorfológicas por meio de dados ASTER/Terra
}

\author{
Flávio Fortes Camargo ${ }^{1}$, Teresa Gallotti Florenzano², Cláudia Maria de Almeida ${ }^{2}$ \\ \& Cleber Gonzales de Oliveira ${ }^{1}$
}

\begin{abstract}
Resumo O objetivo desta pesquisa foi o desenvolvimento de um método semi-automatizado de mapeamento de unidades geomorfológicas, utilizando análise de imagens orientada a objeto e dados ASTER/Terra. A área de estudo foi o município de São José dos Campos/SP. Com este intuito, foram utilizadas redes semânticas hierárquicas (para o armazenamento e reprodução do conhecimento especialista), aliadas à lógica nebulosa e a um conjunto de variáveis multiespectrais, texturais e geomorfométricas. As variáveis texturais e geomorfométricas foram extraídas de um MDE (com acurácia conhecida), gerado por meio do par estereoscópico de imagens do sensor ASTER/Terra. Para a análise, objetos foram gerados por meio de uma segmentação multiresolução, constituída de quatro níveis e considerando algumas variáveis específicas. A rede semântica hierárquica foi inicialmente concebida para classificar quatro macro-unidades geomorfológicas e posteriormente foi detalhada, permitindo gerar onze classes de unidades geomorfológicas. A avaliação da classificação foi realizada por meio de estatísticas (acurácia global e índice Kappa) derivadas de uma matriz de contingência, considerando os objetos da segmentação, obtida da comparação com um mapa de referência. Os valores de acurácia global (86\%) e índice Kappa (83\%) indicam uma forte concordância. Concluiu-se que a análise de imagens orientada a objeto mostrou-se adequada para a semi-automação de procedimentos relacionados ao mapeamento geomorfológico.
\end{abstract}

Palavras-chave: ASTER, MDE, segmentação multiresolução, redes semânticas, lógica nebulosa.

\begin{abstract}
Cognitive approaches for the identification of geomorphological units using ASTER/Terra data. This research aimed to develop a semi-automated geomorphological mapping method using objectbased image analysis and ASTER/Terra data. The study area was the municipality of São José dos Campos, in São Paulo State, Brazil. For this purpose, hierarchical semantic networks (meant for the storage and reproduction of expert knowledge), together with fuzzy logic and a set of multispectral, textural, and geomorphometric variables, were used. The textural and geomorphometric variables were extracted from a DEM (with known accuracy), generated from a pair of stereoscopic ASTER/Terra images. For the analysis, objects were generated by a four-level multiresolution segmentation, taking into account specific variables. The hierarchical semantic net was initially conceived to classify the geomorphological macrounits and was then further detailed to allow a finer classification, which amounted to eleven classes of detailed geomorphological units. In order to assess the classification results, object-based statistical indices (global accuracy and Kappa index) were derived from a contingency table, obtained by comparing the classified scene and a reference map. The values of the global accuracy $(86 \%)$ and Kappa $(83 \%)$ indices indicate a strong agreement. It follows that the object-based image analysis has shown to be a suitable method for semi-automated procedures in geomorphological mapping.
\end{abstract}

Keywords: ASTER, DEM, multiresolution segmentation, semantic nets, fuzzy logic.

INTRODUÇÃO Mapas geomorfológicos são imprescindíveis em estudos e atividades de intervenção no meio físico. Esses mapas fornecem informações relevantes às pesquisas geomorfológicas e são úteis em atividades aplicadas, tais como inventários de recursos naturais, prevenção de desastres e planejamento urbano e rural.

O sensoriamento remoto é uma das principais fontes de dados para as atividades de mapeamento geomorfológico. Desde as suas origens, as fotografias aéreas têm sido amplamente utilizadas em procedimentos monoscópicos e estereoscópicos de interpretação visual
(Verstappen 1972, Klimaszewski 1982, Zuidam 1986, Smith et al. 2006). Atualmente, uma ampla gama de novos sensores, aerotransportados e orbitais, adquire dados (monoscópicos e estereoscópicos) de variadas resoluções espaciais nas faixas espectrais do visível e de microondas. Aliado a isso, o emprego de métodos fotogramétricos (Giles \& Franklin 1998), radargramétricos, interferométricos (Toutin \& Gray 2000) e de varreduras a laser (Lohani \& Mason 2001) possibilita a extração de modelos digitais de elevação (MDEs), úteis na caracterização e mapeamento do relevo.

1 - Instituto Nacional de Pesquisas Espaciais - INPE, Programa de Pós-Graduação em Sensoriamento Remoto, São José dos Campos (SP), Brasil. E-mails: fortes@dsr.inpe.br, cleber@dsr.inpe.br

2 - Instituto Nacional de Pesquisas Espaciais - INPE, Divisão de Sensoriamento Remoto - DSR, São José dos Campos (SP), Brasil.

E-mails: teresa@dsr.inpe.br, almeida@dsr.inpe.br 
Paralelamente ao avanço tecnológico dos sensores, inovações nas ciências da computação têm propiciado o desenvolvimento de algoritmos avançados para análise de imagens de sensoriamento remoto e sistemas para automação de tarefas de mapeamento. Com relação aos primeiros, destacam-se os algoritmos de segmentação que agregam pixels em objetos bidimensionais (segmentos), uniformes e disjuntos (Muñoz 2003, Mueller et al. 2004) e, desse modo, permitem a exploração de uma gama maior de atributos (Schiewe et al. 2001, Miliaresis \& Argialas 2002). No que diz respeito à automação, esta pode ser realizada por meio de sistemas computacionais convencionais (SCs) ou sistemas computacionais especialistas (SEs). Os SCs realizam processamento algorítmico e são guiados pelas variáveis estatísticas dos dados, enquanto os SEs empregam estratégias de modelagem baseadas no conhecimento temático ou específico (Moore 2000).

Redes semânticas e modelagem apoiada em análise orientada a objeto (AOO) têm sido empregadas na realização de tais estratégias de modelagem baseadas no conhecimento do especialista. Essas redes são grafos que formalizam e representam o conhecimento humano por meio de um conjunto de nós conectados por arcos. De modo geral, os nós representam conceitos, e os arcos, as relações entre eles (Tonjes et al. 1999). O conceito, unidade básica dessa metodologia, combina estrutura (atributos) e comportamento (operações) dos dados em uma única entidade. As suas principais características, oriundas da metodologia de AOO, são: (i) identidade, (ii) classificação, (iii) polimorfismo e (iv) herança (Rumbaugh et al. 1991). Os SEs também utilizam medidas de incerteza, tais como lógica nebulosa ou análise bayesiana (Tonjes et al. 1999, Moore 2000, Moore et al. 2003).

Atualmente, há o SE comercial Definiens, que realiza tarefas de interpretação de imagens de sensoriamento remoto. Esse SE emprega segmentação multiresolução (na obtenção dos objetos da análise), redes semânticas hierárquicas e modelagem orientada a objeto (modelagem do conhecimento), além de lógica nebulosa (tratamento de incertezas) (Benz et al. 2004). A segmentação multiresolução emprega o método de crescimento de regiões para criar objetos homogêneos a partir de pixels sementes. Utiliza os critérios fator de escala, cor, compacidade e suavidade. A cor se baseia nas características espectrais da imagem, e os dois últimos compõem o critério de forma (Baatz \& Schäpe 2000). Segundo Kressler e Steinnocher (2006), um alto valor de "compacidade" conduz a segmentos menores e muito compactos, e conseqüentemente, é mais adequado para alvos feitos pelo homem, enquanto um alto valor de "suavidade" conduz a segmentos otimizados para terem bordas suaves, as quais são por sua vez mais adequadas para objetos naturais.

As redes semânticas hierárquicas e a modelagem orientada a objeto incrementam a capacidade de análise e extração de informações, pois permitem o entendimento das características de contexto e das dependências hierárquicas entre objetos. $\mathrm{O}$ emprego de conjuntos nebulosos, por sua vez, possibilita o adequado tratamento das incertezas inerentes aos dados de sensoriamento remoto (Benz et al. 2004). Exemplos da aplicação em atividades semi-automatizadas de mapeamento geomorfológico utilizando essa plataforma podem ser encontrados em Asselen \& Seijmonsbergen (2006), Schneevoigt et al. (2008) e Camargo (2008).

Pelo exposto, os cenários tecnológicos e metodológicos atuais tornam possível a realização de inventários geomorfológicos rápidos, precisos e sistematizados. Isso é de suma importância para a gestão e planejamento, sobretudo em países em desenvolvimento e com grandes extensões territoriais, tal como o Brasil, onde os mapas existentes se restringem aos inventários sistemáticos realizados pelo projeto RADAMBRASIL (DNPM 1983) na escala 1:1.000.000, pelo IPT (1981) na escala 1:1.000.000, e por Ross \& Moroz (1997) na escala 1:500.000, sendo que somente o primeiro deles tem abrangência nacional.

Nesse contexto, o objetivo deste trabalho é apresentar os resultados da aplicação de um método semiautomatizado de mapeamento geomorfológico, utilizando o SE Definiens e dados ASTER/Terra do subsistema sensor Visible Near-Infrared (VNIR). Acrescenta-se também uma avaliação qualitativa e quantitativa dos resultados, seguida de uma discussão crítica das potencialidades e limitações dos dados e da metodologia.

ÁREA DE ESTUDO A área de estudo, com 1.098,6 $\mathrm{km}^{2}$, é o município de São José dos Campos (SP), localizado no médio vale do rio Paraíba do Sul (Fig. 1). Esse município foi selecionado para análise devido à sua diversidade geomorfológica, existência de estudos anteriores e facilidade de acesso.

O médio vale do rio Paraíba do Sul está inserido em um sistema de montanhas constituído pelas Serras do Mar e da Mantiqueira. Esse sistema é a mais destacada feição orográfica da borda atlântica do continente sul-americano, e sua história evolutiva data do PréCambriano (Almeida \& Carneiro 1998). Destacam-se, em ordem cronológica, três grandes conjuntos de eventos responsáveis pela sua configuração fisiográfica: (i) sucessivas interações entre placas continentais (no Proterozóico), que formaram faixas móveis acrescionárias, colisionais e transpressionais (Almeida \& Carneiro 1998); (ii) geração da superfície de aplainamento Japi (entre o Cretáceo Superior e o Terciário Inferior) por meio da erosão de corpos rochosos (ígneos e metamórficos, principalmente) (Almeida 2000); e (iii) tafrogênese (início no Paleógeno), sedimentação e preenchimento de hemi-grabens (Almeida 2000).

Esses processos definiram as características litológicas e geomorfológicas da área de estudo. Com relação à litologia, esta é composta de rochas cristalinas (ígneas e metamórficas) dos complexos: (i) Amparo, (ii) Embu, (iii) Paraíba do Sul e (iv) Paraisópolis. Ocorrem também rochas sedimentares da formação Taubaté (Terciário Superior) e depósitos quaternários (aluviões). Nos complexos citados, predominam gnaisses (datando do Arqueano ao Proterozóico Médio) e suítes graníticas sin e pós-tectônicas (Proterozóico Superior), ambos ocasionados pelas movimentações crustais da orogêne- 


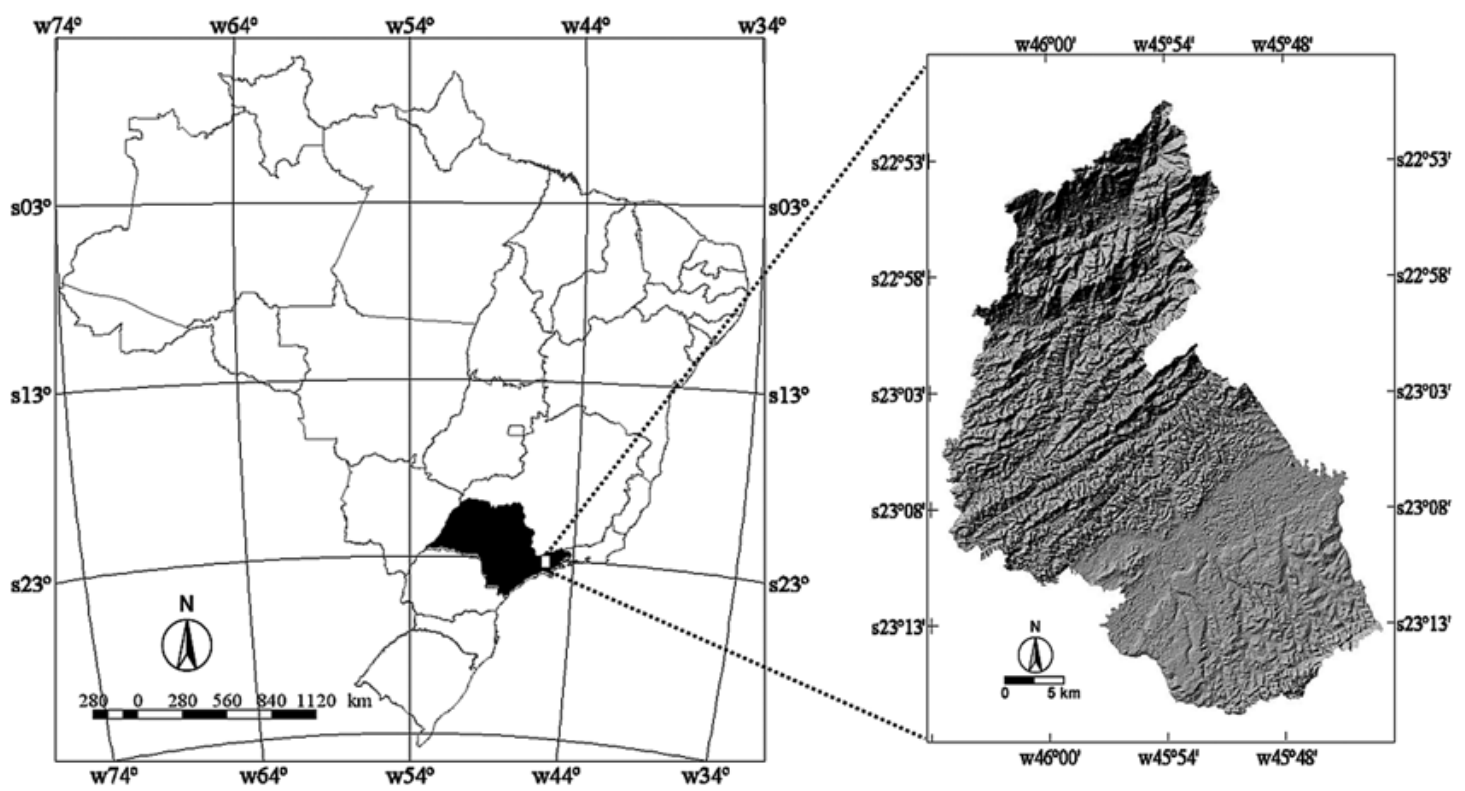

Figura 1 - Localização da área de estudo: estado de São Paulo destacado em preto, à esquerda, e representação do relevo sombreado do município de São José dos Campos, à direita.

se Brasiliana (Pré-Cambriano) (DNPM 1983).

Nas rochas cristalinas, a geomorfologia da área de estudo é caracterizada por morrotes, morros e montanhas (Florenzano \& Csordas 1993). De acordo com Almeida \& Carneiro (1998), planaltos e escarpas são sustentados por rochas mais resistentes, enquanto lineamentos rochosos e a rede de drenagem são condicionados por falhas, fraturas e zonas de cisalhamento. Em terrenos sedimentares, ocorrem planícies aluviais (Florenzano \& Csordas 1993), terraços (Verdade \& Hungria 1966) e colinas terciárias (Florenzano \& Csordas 1993). Cabe destacar a ocorrência de diversos padrões de alvéolos ou planícies aluviais intermontanas de menor porte. Verdade \& Hungria (1966) verificaram a existência de dois níveis de terraços fluviais na margem direita (sudoeste) do rio Paraíba do Sul. Isso ocorre devido à tendência do rio em se deslocar no sentido noroeste (Verdade \& Hungria 1966), ocasionada pela inclinação norte-noroeste do hemi-graben (Almeida 2000).

\section{MÉTODOS DE TRABALHO}

Material No desenvolvimento desta pesquisa, foram utilizados os seguintes materiais: (i) imagens ASTER/ Terra do subsistema Visible Near-InfraRed (VNIR) (bandas $3 \mathrm{~N}$ e $3 \mathrm{~B}$; entre 0,78 e $0,86 \mu \mathrm{m}$ ); (ii) arquivo vetorial de eixo de logradouros; (iii) arquivo vetorial da rede hidrográfica; (iv) arquivos vetoriais de curvas de nível; (v) arquivos de pontos cotados, (vi) arquivos vetoriais com a delimitação das unidades geotécnicas; (vii) arquivos com coordenadas (E, N e H) de 109 pontos obtidos a partir de levantamento de campo realizado com equipamentos GPS (Global Positioning System) geodésicos de uma freqüência; e (viii) equipamentos Zscreen 2000 para visualização estereoscópica.

As imagens ASTER/Terra, de 31/08/2004, foram adquiridas no nível de processamento L1B. Os produtos deste nível de processamento consistem em imagens com os coeficientes radiométricos e geométricos aplicados, e co-registradas com as demais bandas do sistema sensor ASTER/Terra. Os coeficientes radiométricos representam os ganhos e offsets que devem ser aplicados para a calibração dos 5.000 detectores CCD (charge-coupled device). Por sua vez, os coeficientes geométricos projetam a imagem para o sistema UTM e as orientam no sentido da órbita da plataforma. Cabe destacar que as imagens utilizadas neste trabalho apresentam uma resolução espacial de $15 \mathrm{~m}$ e uma razão base/altura da plataforma de 0,6 (Abrams et al. 1999).

Os arquivos vetoriais, na escala 1:10.000, compõem o banco de dados geográficos "Cidade Viva", disponível gratuitamente na Prefeitura Municipal de São José dos Campos, SP (PMSJC). As coordenadas GPS foram obtidas junto aos seguintes órgãos: Instituto de Estudos Avançados da Aeronáutica (IEAv), Instituto Nacional de Pesquisas Espaciais (INPE) e Fundação de Ciência, Aplicações e Tecnologia Espaciais (FUNCATE). Esses órgãos realizaram a conversão das altitudes geométricas em altitudes ortométricas. Os equipamentos ZScreen 2000 foram cedidos pelo INPE.

Com relação aos aplicativos, foram empregados os pacotes de processamento de imagens PCI Geomatica 10.0.3 e ENVI 4.3; o SIG SPRING 4.3.3 e o sistema de interpretação de imagens Definiens Professional 5.0.

Pré-processamento dos dados O pré-processamento dos dados foi constituído da geração e validação do MDE e do emprego deste na extração das variáveis geomorfométricas e texturais utilizadas nas etapas de segmentação multiresolução e classificação orientada a objeto.

Para a extração do MDE, foi utilizado o aplicativo PCI Geomatica 10.0.3 (módulo OrthoEngine), conforme os seguintes procedimentos: 1) coleta de pontos 
de controle e pontos de enlace; 2) estimativa dos parâmetros do modelo matemático e orientação do par estereoscópico; 3) geração de imagens com geometria epipolar; 4) cálculo das paralaxes por estéreo-correlação; e 5) geração e geocodificação do MDE. Nos passos 1 e 2 , utilizaram-se os dados de efemérides e atitude do sistema sensor ASTER/Terra (disponíveis nos metadados das imagens), o modelo matemático Toutin, 43 pontos de controle (PCs) 3D e 90 pontos de enlace (PEs) 2D.

$\mathrm{O}$ modelo utilizado se baseia nas condições e equações de colinearidade (para imagens individuais) e coplanaridade (para imagens estereoscópicas), e, portanto, baseia-se no modelo fotogramétrico rigoroso (Toutin 2004a, 2006). Sabendo-se que os parâmetros necessários para as correções individuais (sensor/plataforma; rotação da terra e projeção cartográfica) são correlacionados, o modelo Toutin reduz esses parâmetros a um conjunto descorrelacionado, a partir dos quais realiza, simultaneamente, todas as correções mencionadas (Toutin 2004a). A acurácia posicional do modelo pode ser melhorada com o uso de PCs, empregados em um procedimento iterativo de refinamento pelo método dos mínimos quadrados (Toutin 2002, 2004a, 2004b, 2006).

As coordenadas planialtimétricas dos PCs foram obtidas por meio de uma base de eixo de logradouros (coordenadas E e N) e de um MDE (coordenada $\mathrm{H})$ gerado de curvas de nível e pontos cotados. Com relação aos PEs, Toutin (2002, 2004a, 2004b, 2006) os define como pontos homólogos, coletados simultaneamente entre as imagens do par estereoscópico,os quais fornecem maior rigidez ao modelo.

Após a orientação do par estereoscópico e extração das imagens epipolares, efetuou-se o cálculo automático das paralaxes. Este foi realizado a partir de janelas de busca e correlação que localizam pixels homólogos entre as imagens (Ehlers \& Welch 1987). A medida de correlação empregada pelo algoritmo utilizado pelo módulo OrthoEngine é o coeficiente normalizado de correlação cruzada (PCI Geomatics 2006).

Para a validação do MDE, foram utilizados 109 pontos obtidos em campo com equipamentos GPS. Esses pontos e o MDE ASTER/Terra foram referenciados ao mesmo datum horizontal (SAD69/Brasil) e sistema de projeção (UTM). Desse modo, foram obtidas as discrepâncias entre o MDE ASTER/Terra e as altitudes dos pontos GPS (altimetria MDE - altimetria GPS). Posteriormente, realizou-se uma análise estatística descritiva dos resíduos e também foi aplicado o teste estatístico $t$-Student para avaliar se a média desses não apresentava tendência. Os resultados obtidos foram confrontados com outros trabalhos científicos, que também avaliaram a acurácia altimétrica dos dados ASTER/Terra e serviram de indicativo da qualidade do MDE empregado na classificação.

Após a validação, extraíram-se as variáveis do modelo cognitivo de classificação. A banda $3 \mathrm{~N}$ foi ortorretificada com base nos PCs coletados anteriormente e no MDE ASTER/Terra gerado, para que fosse então utilizada como uma variável multiespectral no modelo. A rede de drenagem foi fornecida pela PMSJC, e as demais variáveis foram derivadas do MDE ASTER/Terra.
O quadro I apresenta as variáveis do modelo cognitivo.

A declividade é uma das componentes do vetor obtido da primeira derivação da superfície (MDE) e caracteriza a inclinação da vertente. A segunda derivação fornece as curvaturas horizontal e vertical. A curvatura vertical evidencia áreas de aceleração e desaceleração gravitacional, a partir da caracterização das vertentes em tipos côncavo, convexo ou retilíneo (Shary 2007). A curvatura horizontal destaca as linhas de convergência e divergência do escoamento superficial (Shary 2007).

Para a mensuração das variáveis texturais empregou-se a matriz de co-ocorrência dos níveis de cinza (Grey Level Co-ocurrence Matrix - GLCM). O método GLCM consiste em um histograma bi-dimensional de níveis de cinza de pares de pixels que estão em uma relação espacial definida pelo comprimento $\delta$ e pela orientação $\theta$ do segmento de reta que os une (PCI Geomatics 2006; Clausi, 2002).

O fluxo acumulado é um dos subprodutos do processo de extração automática de redes de drenagens e seu valor, em um ponto y qualquer, consiste na quantidade de pixels (a montante de y) que contribuem para o escoamento superficial nesse ponto (PCI Geomatics 2006).

Classes da legenda e mapa de referência A nomenclatura das classes de relevo foi adaptada do mapa geomorfológico do estado de São Paulo (IPT 1981) (escala 1: 1.000.000). Para a definição das classes (Quadro II), foram necessárias as interpretações visuais do par estereoscópico das imagens epipolares ASTER/Terra e do MDE derivado destas e, também, um trabalho de campo (realizado no dia 11/04/2007) para a identificação de níveis de terraços fluviais, mencionados por Verdade \& Hungria (1966).

A legenda segue a proposta do sistema ITC (Verstappen \& Zuidam 1991) e destaca os aspectos morfogenéticos dominantes: (i) formas estruturais-denudacionais (matizes de roxo); (ii) formas de denudacão (matizes de marrom) e (iii) formas de agradação (matizes de verde). Foram acrescentadas à legenda informações sobre a litologia, extraídas da carta geotécnica digital.

Devido à inexistência de mapas geomorfológicos detalhados (escalas superiores a 1:100.000), restituiu-se, um mapa de referência a partir do par estereos-

Quadro I - Resumo das variáveis do modelo cognitivo.

\begin{tabular}{l|l}
\hline Tipo de Variável & Descrição \\
\hline Multiespectral & Imagem ortorretificada da Banda 3N \\
\hline \multirow{3}{*}{ Geomorfométrica } & Altimetria (MDE ASTER) \\
& Declividade \\
& Curvatura vertical \\
& Curvatura horizontal \\
\hline \multirow{3}{*}{ Textural } & Segundo momento angular \\
& Entropia \\
& Desvio padrão \\
\hline \multirow{3}{*}{ Outras } & Imagem temática da rede de drenagem \\
& Grade de fluxo acumulado \\
& Relevo sombreado \\
\hline
\end{tabular}


cópico das imagens epipolares de forma independente à classificação orientada a objeto. Esse mapa foi empregado na validação dos resultados.

Segmentação multiresolução e classificação orientada a objeto multinível Devido à complexa fisiografia da área de estudo, não foi possível delimitar as classes propostas na legenda a partir de um único nível de segmentação. Desse modo, foram realizados quatro níveis de segmentação, sendo que um foi empregado na classificação dos corpos d'água, outro na estimativa da densidade de drenagem e os restantes na classifica- ção das unidades geomorfológicas. Assim, essas unidades foram classificadas em duas etapas hierárquicas: (a) grandes unidades morfogeneticamente homogêneas, denominadas de macro-unidades geomorfológicas (Quadro II), e (b) unidades geomorfológicas detalhadas (Quadro II). A densidade de drenagem, por sua vez, forneceu atributos para a classificação.

Inicialmente, foram definidos três níveis de segmentação (Fig. 2): (1) corpos d'água; (2) macrounidades geomorfológicas, e (3) unidades baseadas no cálculo da densidade de drenagem, razão entre a área da rede hidrográfica e a área de cada objeto neste nível. Na

Quadro II - Classes de unidades geomorfológicas, suas principais características litológicas e processos morfogenéticos predominantes (células com tracejado representam ausência de informação na carta geotécnica).

\begin{tabular}{|c|c|c|c|}
\hline Macro-unidades geomorfológicas & Unidades geomorfológicas detalhadas & Litologia & Processos dominantes \\
\hline \multirow{2}{*}{ Planícies Aluviais } & Planícies Aluviais & Sedimentos argilo-arenosos. & \multirow{3}{*}{ Agradação } \\
\hline & Terraços Fluviais & Sedimentos argilo-arenosos. & \\
\hline Planícies Aluviais Intermontanas & Planícies Aluviais Intermontanas & Sedimentos arenosos. & \\
\hline \multirow{3}{*}{ Colinas Sedimentares } & Colinas Amplas & Sedimentos arenosos. & \multirow{3}{*}{ Denudacão } \\
\hline & Colinas Pequenas & Sedimentos argilo-arenosos. & \\
\hline & Colinas Tabulares & Sedimentos arenosos. & \\
\hline \multirow{5}{*}{ Serras/Montanhas/Morros } & Morros Arredondados & Migmatitos, gnaisses, xistos e filitos. & \multirow{5}{*}{$\begin{array}{l}\text { Tectonismo- } \\
\text { Denudação }\end{array}$} \\
\hline & Morros Alongados e Paralelos & $\begin{array}{l}\text { Migmatitos, gnaisses, xistos, filitos e } \\
\text { suítes graníticas. }\end{array}$ & \\
\hline & Serras Médias-Altas & $\begin{array}{l}\text { Migmatitos, gnaisses, xistos, filitos e } \\
\text { suítes graníticas. }\end{array}$ & \\
\hline & Serras Altas & - & \\
\hline & Serras Altas e Escarpadas & 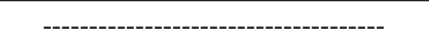 & \\
\hline
\end{tabular}

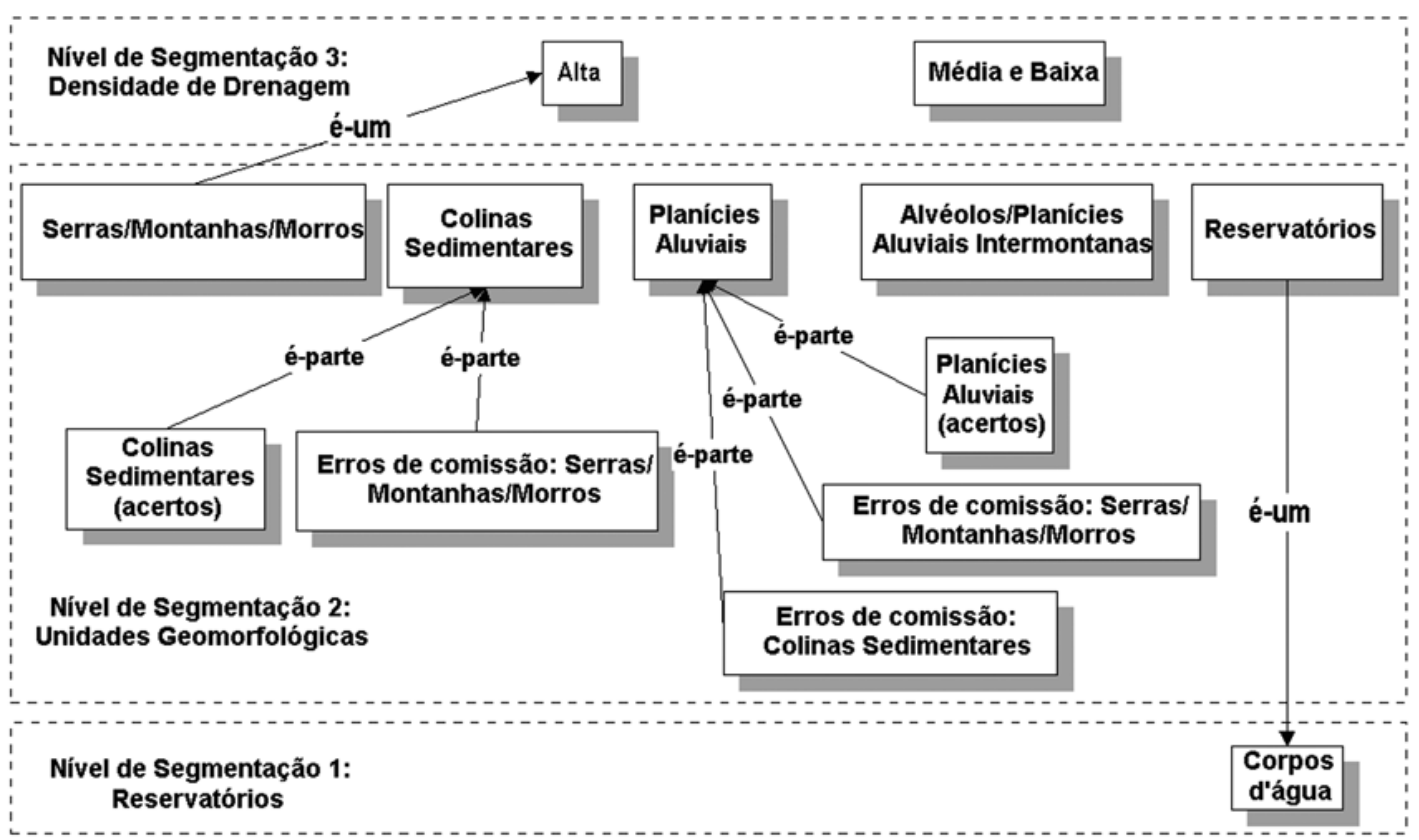

Figura 2 - Rede semântica hierárquica empregada na classificação das macro-unidades geomorfológicas. 
tabela 1, são apresentadas as variáveis e os parâmetros empregados na segmentação mencionada. Desta forma, nesta rede inicial foram classificados os corpos d'água, a densidade de drenagem (em "Alta" e "Média e Baixa") e as macro-unidades geomorfológicas "Serras/ Montanhas/Morros", "Planícies Aluviais", "Planícies Aluviais Intermontanas" e "Colinas Sedimentares". Na análise exploratória, empregaram-se histogramas com valores amostrais dos atributos, calculados a partir dos objetos da segmentação. A tabela 2 apresenta os atributos das macro-unidades geomorfológicas.

No entanto, em algumas classes verifica-se a sobreposição de valores/intervalos. Essa confusão foi minimizada através: (i) da utilização do operador nebuloso $A N D$ e suas funções flexíveis: gaussianas, trapezoidais, exponenciais etc. (McBratney \& Odeh 1997); e (ii) a partir do conceito de herança oriundo da AOO. Esse conceito permitiu a criação de subclasses (Tab. 3), as quais identificaram os objetos corretamente classificados e aqueles referentes aos erros de comissão.

O operador nebuloso $A N D$, tal como o operador booleano $A N D$, tem por característica retornar valores comuns entre dois conjuntos (o qual fornece o menor dos dois valores de pertinência de cada conjunto). Desse modo, este operador possibilita a combinação de atributos considerados únicos a uma dada classe. Como exemplo disto, destacam-se as macro-unidades geomorfológicas "Serras/Montanhas/Morros" e "Colinas Sedimentares", as quais têm valores comuns do atributo média da altimetria no intervalo entre 572 e $688 \mathrm{~m}$, e valores comuns de média da declividade no intervalo entre $4,9^{\circ} \mathrm{e}$ $12^{\circ}$ (ver Tab. 2). Neste caso, a inserção do atributo média da entropia entre 1,2 e 2,2 (existente somente nas áreas de colinas) restringe ainda mais os resultados do operador nebuloso $A N D$ e reduz drasticamente a confusão entre as classes mencionadas. Com relação ao conceito de herança, este foi explorado a partir da criação de subclasses (Tab. 3 e Fig. 2) que herdaram os atributos das
Tabela 1 - Variáveis e parâmetros (e = fator de escala; $c$ $=$ cor $; f=$ forma $;$ comp.$=$ compacidade e suav.$=$ suavidade) utilizados nos procedimentos de segmentação.

\begin{tabular}{l|c|c|c|c|c|c}
\hline Etapa/Nível & $\begin{array}{c}\text { Variável da } \\
\text { Segmentação }\end{array}$ & $\mathrm{e}$ & $\mathrm{c}$ & $\mathrm{f}$ & comp. & suav. \\
\hline $\begin{array}{l}\text { 1. Extração dos } \\
\text { reservatórios }\end{array}$ & $\begin{array}{c}\text { Banda 3N } \\
\text { (número digital) }\end{array}$ & 30 & 0,8 & 0,2 & 0,5 & 0,5 \\
\hline $\begin{array}{l}\text { 2. Extração das } \\
\text { macro-unidades } \\
\text { geomorfológicas }\end{array}$ & $\begin{array}{c}\text { Altimetria } \\
\text { (MDE) }\end{array}$ & 50 & 0,7 & 0,3 & 0,3 & 0,7 \\
\hline $\begin{array}{l}\text { 3. Cálculo da } \\
\text { densidade de } \\
\text { drenagem }\end{array}$ & $\begin{array}{c}\text { Relevo } \\
\text { Sombreado }\end{array}$ & 200 & 0,1 & 0,9 & 0,5 & 0,5 \\
\hline $\begin{array}{l}\text { 4 Extração } \\
\text { das unidades } \\
\text { geomorfológicas } \\
\text { detalhadas }\end{array}$ & $\begin{array}{c}\text { Relevo } \\
\text { Sombreado }\end{array}$ & 200 & 0,1 & 0,9 & 0,5 & 0,5 \\
\hline
\end{tabular}

Tabela 2 - Atributos das macro-unidades geomorfológicas e reservatórios.

\begin{tabular}{l|l}
\hline Unidades & Atributos \\
\hline Serras/Montanhas/Morros & $\begin{array}{l}\text { alta densidade de drenagem (nível 3); } \\
\text { média da altimetria entre } 572 \text { e } 2100 \mathrm{~m} ; \\
\text { média da declividade entre } 4,9^{\circ} \text { e } 34,9^{\circ} .\end{array}$ \\
\hline Colinas Sedimentares & $\begin{array}{l}\text { média da altimetria entre } 560 \text { e } 688 \mathrm{~m} ; \\
\text { média da entropia entre } 1,2 \text { e } 2,2 ; \\
\text { média da declividade entre } 2,5^{\circ} \text { e } 12^{\circ} .\end{array}$ \\
\hline Planícies Aluviais & $\begin{array}{l}\text { média da entropia entre }-0,01 \text { e } 1,5 ; \\
\text { média da declividade entre } 1,4^{\circ} \text { e } 10^{\circ} .\end{array}$ \\
\hline $\begin{array}{l}\text { Planícies Aluviais } \\
\text { Intermontanas }\end{array}$ & $\begin{array}{l}\text { amplitude altimétrica entre } 10 \text { e } 12 \mathrm{~m} ; \\
\text { média da altimetria entre } 678 \text { e } 687 \mathrm{~m} ; \\
\text { média da declividade entre } 2,88^{\circ} \text { e } 4,75^{\circ} .\end{array}$ \\
\hline Reservatórios & existência de corpos d'água no nível 1. \\
\hline
\end{tabular}

Tabela 3 - Atributos empregados no refinamento das macro-unidades geomorfológicas, a partir de subclasses de erros de comissão.

\begin{tabular}{l|l|l}
\hline Unidades & Subclasses & Atributos \\
\hline \multirow{4}{*}{$\begin{array}{l}\text { Colinas } \\
\text { Sedimentares }\end{array}$} & Colinas Sedimentares (acertos) & $\begin{array}{l}\text { borda relativa à classe Serras/Montanhas/Morros (0 } \\
\text { a 1). } \\
\text { *a pertinência é alta em 0 (zero) e diminui } \\
\text { exponencialmente em direção a 1. }\end{array}$ \\
\cline { 2 - 3 } & $\begin{array}{l}\text { Erros de Comissão: Serras/ } \\
\text { Montanhas/Morros }\end{array}$ & $\begin{array}{l}\text { borda relativa à classe Serras/Montanhas/Morros (0 } \\
\text { a 1). } \\
\text { *a pertinência é baixa em 0 (zero) e aumenta } \\
\text { exponencialmente em direção a 1. }\end{array}$ \\
\hline \multirow{5}{*}{$\begin{array}{l}\text { Planícies } \\
\text { Fluviais }\end{array}$} & $\begin{array}{l}\text { diferença média do fluxo acumulado entre a classe } \\
\text { Colinas Sedimentares (-850 a 2.050); } \\
\text { borda relativa à classe Serras/Montanhas/Morros (0 } \\
\text { a 0,5). }\end{array}$ \\
\cline { 2 - 3 } & $\begin{array}{l}\text { Erros de Comissão: Serras/ } \\
\text { Montanhas/Morros }\end{array}$ & $\begin{array}{l}\text { borda relativa à classe Serras/Montanhas/Morros (0,4 } \\
\text { a 0,64). }\end{array}$ \\
\cline { 2 - 3 } & $\begin{array}{l}\text { Erros de Comissão: Colinas } \\
\text { Sedimentares }\end{array}$ & $\begin{array}{l}\text { diferença média do fluxo acumulado entre a classe } \\
\text { Colinas Sedimentares (-850 a 2.050); } \\
\text { variância da curvatura horizontal (16,35 a 17). }\end{array}$ \\
\hline
\end{tabular}


classes da legenda e acrescentaram novos atributos para a identificação dos erros de comissão. Esta estrutura hierárquica evitou a confusão entre as subclasses criadas e as classes já existentes e permitiu o incremento dos acertos da classificação. Este incremento foi possível a partir da agregação das classes por significado semântico, ou seja, as subclasses de erros são reinseridas no domínio de suas classes verdadeiras por meio do recurso de agrupamento por similaridade de legenda (Groups), disponível na plataforma Definiens.

Por exemplo, os objetos das subclasses de erros de comissão relativas à classe "Serras/Montanhas/Morros" e inseridas nas classes "Planícies Fluviais" e "Colinas Sedimentares" (Tab. 3 e Fig. 2) são considerados objetos da classe "Serras/Montanhas/Morros".

Nas tabelas 4 e 5, são apresentados, respectivamente, os atributos empregados nas classificações dos corpos d'água e da densidade de drenagem. Na tabela 6 , encontram-se os atributos das subclasses de erros de comissão, utilizadas no refinamento da densidade de drenagem.

Na seqüência, para a segmentação das unidades geomorfológicas detalhadas, foi necessária a fusão dos objetos do nível 2 (macro-unidades geomorfológicas). Para tal, utilizou-se o recurso de agrupamento de objetos (merge), disponível na plataforma Definiens. Assim, os objetos de cada macro-unidade geomorfológica foram agrupados e, posteriormente, houve a segmentação das unidades geomorfológicas detalhadas, no interior desses objetos. Essa segmentação foi realizada em um novo nível a partir da imagem de relevo sombreado. Como o procedimento de agrupamento de objetos realiza a fusão de objetos de níveis superiores, foi necessária a reorganização dos níveis para a preservação das bordas do nível com as unidades de densidade de drenagem. Desse modo, as unidades geomorfológicas detalhadas foram segmentadas no nível 1; a densidade de drenagem ocupou o nível 2; os reservatórios ocuparam o nível 3; e, por fim, as macro-unidades geomorfológicas ficaram no nível 4.

Com relação às variáveis utilizadas na segmentação das unidades geomorfológicas detalhadas, testes com a declividade e com o fluxo acumulado foram realizados. A variável declividade, apesar de apresentar bons resultados visuais, gerou um grande número de objetos pequenos (supersegmentação), que não são adequados para os subseqüentes procedimentos de classificação. Situação semelhante ocorreu nos testes que combinaram a declividade com a grade de fluxo acumulado (a qual destaca os talvegues). Nesse caso, os limites foram mais precisos, porém, os objetos também possuíam tamanhos inadequados.

A técnica de relevo sombreado permite o realce visual de lineamentos, fraturas e feições geomorfológicas (Soulakellis et al., 2006). Neste trabalho o relevo sombreado foi gerado a partir de um ângulo de elevação solar moderado $\left(45^{\circ}\right)$ e azimute $\left(315^{\circ}\right)$ perpendicular às principais falhas do hemi-graben. Esta configuração de iluminação, aliada a um peso maior para os parâmetros forma e compacidade, foi adequada para a delimitação das unidades finais e, também, para a geração de obje-
Tabela 4 - Atributos da classe corpos d'água.

\begin{tabular}{l|l}
\hline Classe & Atributos \\
\hline Corpos d'água & $\begin{array}{l}\text { média da altimetria entre } 609 \text { e } 707 \mathrm{~m} ; \\
\text { média do número digital da banda 3N entre } 14 \\
\text { e } 46 .\end{array}$ \\
\hline
\end{tabular}

Tabela 5 - Atributos empregados na classificação da densidade de drenagem.

\begin{tabular}{l|l|l}
\hline $\begin{array}{l}\text { Nível de } \\
\text { segmentação }\end{array}$ & Classes & Atributos \\
\hline \multirow{2}{*}{ Hidrografia } & Canais Fluviais & $\begin{array}{l}\text { média do número digital da } \\
\text { imagem temática da drenagem } \\
\neq 255 .\end{array}$ \\
\cline { 2 - 3 } & Não-Canais & $\begin{array}{l}\text { média do número digital da } \\
\text { imagem temática da drenagem } \\
=255 .\end{array}$ \\
\hline \multirow{2}{*}{$\begin{array}{l}\text { Densidade de } \\
\text { Drenagem }\end{array}$} & $\begin{array}{l}\text { Alta Densidade } \\
\text { de Drenagem }\end{array}$ & $\begin{array}{l}\text { área relativa dos canais, por } \\
\text { objeto do nível densidade de } \\
\text { drenagem }(0,044 \text { a } 1) .\end{array}$ \\
\cline { 2 - 3 } & $\begin{array}{l}\text { Média e Baixa } \\
\text { Densidade de } \\
\text { Drenagem }\end{array}$ & $\begin{array}{l}\text { área relativa dos canais, por } \\
\text { objeto do nível densidade de } \\
\text { drenagem }\left(10^{-4} \text { a } 4,35.10^{-2}\right) .\end{array}$ \\
\hline
\end{tabular}

Tabela 6 - Atributos empregados no refinamento da densidade de drenagem, a partir de subclasses de erros de comissão.

\begin{tabular}{l|l|l}
\hline Classe & Subclasses & Atributos \\
\hline \multirow{4}{*}{$\begin{array}{l}\text { Média e Baixa } \\
\text { Densidade de }\end{array}$} & $\begin{array}{l}\text { Média e Baixa } \\
\text { (corretamente } \\
\text { classificado) }\end{array}$ & $\begin{array}{l}\text { borda relativa à classe Alta } \\
\text { Densidade de Drenagem }(0,15 \\
\text { a } 0,9) .\end{array}$ \\
\cline { 2 - 3 } & $\begin{array}{l}\text { Erros de comissão: } \\
\text { Alta Densidade de }\end{array}$ & $\begin{array}{l}\text { borda relativa à classe Alta } \\
\text { Densidade de Drenagem }(0,15 \\
\text { a } 0,9) .\end{array}$ \\
\hline
\end{tabular}

tos de maiores dimensões em área. A tabela 1 apresenta a variável e os parâmetros da segmentação das unidades geomorfológicas detalhadas.

$\mathrm{Na}$ classificação das unidades geomorfológicas detalhadas, realizou-se também uma análise exploratória de atributos, baseada em histogramas com valores amostrais calculados a partir dos objetos da segmentação. As tabelas 7, 8 e 9 apresentam os atributos empregados na classificação semi-automatizada das unidades geomorfológicas detalhadas.

A rede semântica hierárquica inicial foi adaptada, e houve o acréscimo de classes abstratas em um nível hierárquico superior, as quais são subdivididas em subclasses inferiores detalhadas. Em conseqüência disso, as subclasses detalhadas herdam restrições das classes abstratas (relacionamento do tipo é-parte), que minimizam a confusão entre classes. A figura 3 apresenta a rede 
Tabela 7 - Atributos das formas de agradação (unidades geomorfológicas detalhadas).

\begin{tabular}{l|l}
\hline $\begin{array}{l}\text { Formas de } \\
\text { agradação }\end{array}$ & Atributos \\
\hline $\begin{array}{l}\text { Planícies } \\
\text { Aluviais }\end{array}$ & inseridas na macro-unidade Planícies Aluviais. \\
\hline $\begin{array}{l}\text { Planícies } \\
\text { Aluviais } \\
\text { Intermontanas }\end{array}$ & $\begin{array}{l}\text { inseridas na macro-unidade Planícies Aluviais } \\
\text { Intermontanas. }\end{array}$ \\
\hline & $\begin{array}{l}\text { inseridos na macro-unidade Planícies Aluviais; } \\
\text { média da altimetria entre 559,5 e 600m; } \\
\text { exceto para média da curvatura vertical entre -0,17 } \\
\text { e }-9,999 ; \\
\text { exceto para desvio padrão do fluxo acumulado entre } \\
4.500 \text { e } 120.000 \text { pixels. }\end{array}$ \\
\hline
\end{tabular}

semântica hierárquica utilizada na classificação das unidades geomorfológicas detalhadas. Conforme mencionado, observa-se que as classes abstratas "Cotas Altas" e "Cotas Médias-Altas" são utilizadas com propósito de minimizar a confusão entre suas subclasses detalhadas (relacionamento do tipo é-parte). O mesmo ocorre com a classe abstrata "Morros" e suas subclasses detalhadas.

Com o intuito de incrementar os resultados fornecidos pela rede semântica, foram empregadas rotinas de pós-processamentos a partir de um conjunto de algoritmos disponível na plataforma Definiens. Esses algoritmos têm interface gráfica para usuário e podem ser parametrizados. Desse modo, foram empregados dois tipos de algoritmos: (i) find enclosed by class e (ii) find local extrema (Definiens, 2006). O primeiro classifica (ou re-classifica) os objetos de acordo com regras de vizinhança. Por exemplo, classificar todos os objetos não-classificados contidos por objetos da classe "Colinas Sedimentares", como "Colinas Sedimentares". Assim, todos os objetos que satisfaçam essa regra são classificados. O segundo também classifica (ou re-classifica) objetos de acordo com valores extremos
Tabela 8 - Atributos das formas de denudação (unidades geomorfológicas detalhadas).

\begin{tabular}{l|l}
\hline $\begin{array}{l}\text { Formas de } \\
\text { denudação }\end{array}$ & Atributos \\
\hline Colinas & $\begin{array}{l}\text { inseridas na macro-unidade Colinas Sedimentares; } \\
\text { variância da curvatura horizontal entre } 12 \text { e } 16,5 ; \\
\text { exceto para média do segundo momento angular entre } 0,3 \text { e } 0,32 ; \\
\text { exceto para média da entropia entre } 1,0155 \text { e } 1,464 .\end{array}$ \\
\hline Colinas & $\begin{array}{l}\text { inseridas na macro-unidade Colinas Sedimentares; } \\
\text { variância da curvatura horizontal entre 1,5 e 13,7; } \\
\text { exceto para média da entropia entre 1,1 e 1,27. }\end{array}$ \\
\hline Colinas & $\begin{array}{l}\text { inseridas na macro-unidade Colinas Sedimentares; } \\
\text { variância da curvatura horizontal entre } 8 \text { e 21; } \\
\text { exceto para média do segundo momento angular entre } \\
\text { Tabulares }\end{array}$ \\
\hline
\end{tabular}

Tabela 9 - Atributos das formas estruturais-denudacionais (unidades geomorfológicas detalhadas).

\begin{tabular}{|c|c|}
\hline $\begin{array}{l}\text { Formas } \\
\text { estruturais- } \\
\text { denudacionais }\end{array}$ & Atributos \\
\hline $\begin{array}{l}\text { Morros } \\
\text { Arredondados }\end{array}$ & $\begin{array}{l}\text { inseridos na macro-unidade Serras/Montanhas/Morros; } \\
\text { média da altimetria entre } 538 \text { e } 694,5 \mathrm{~m} \text {; } \\
\text { variância da curvatura horizontal entre } 8,4 \text { e } 14,15 \text {; } \\
\text { exceto para variância da curvatura vertical entre } 0,11 \text { e } 0,208 \text {. }\end{array}$ \\
\hline $\begin{array}{l}\text { Morros } \\
\text { Alongados e } \\
\text { Paralelos }\end{array}$ & $\begin{array}{l}\text { inseridos na macro-unidade Serras/Montanhas/Morros; } \\
\text { média da altimetria entre } 538 \text { e } 694,5 \mathrm{~m} \\
\text { valores máximos de altimetria entre } 658 \text { e } 790 \mathrm{~m} \text {. }\end{array}$ \\
\hline $\begin{array}{l}\text { Serras } \\
\text { Médias-Altas }\end{array}$ & $\begin{array}{l}\text { inseridas na macro-unidade Serras/Montanhas/Morros; } \\
\text { valores máximos de altimetria entre } 740 \text { e } 1.130 \mathrm{~m} \text {. }\end{array}$ \\
\hline Serras Altas & $\begin{array}{l}\text { valores máximos de altimetria entre } 1.137 \text { e } 2.150 \mathrm{~m} \text {; } \\
\text { média da altimetria entre } 725 \text { e } 1.300 \mathrm{~m} \text {. }\end{array}$ \\
\hline $\begin{array}{l}\text { Serras Altas e } \\
\text { Escarpadas }\end{array}$ & $\begin{array}{l}\text { inseridas na macro-unidade Serras/Montanhas/Morros; } \\
\text { valores máximos de altimetria entre } 1.137 \text { e } 2.150 \mathrm{~m} \text {; } \\
\text { média da altimetria entre } 930 \text { e } 2.000 \mathrm{~m} \text {; } \\
\text { exceto para média do segundo momento angular } 0,68 \\
\text { a } 0,695 \text {. }\end{array}$ \\
\hline
\end{tabular}

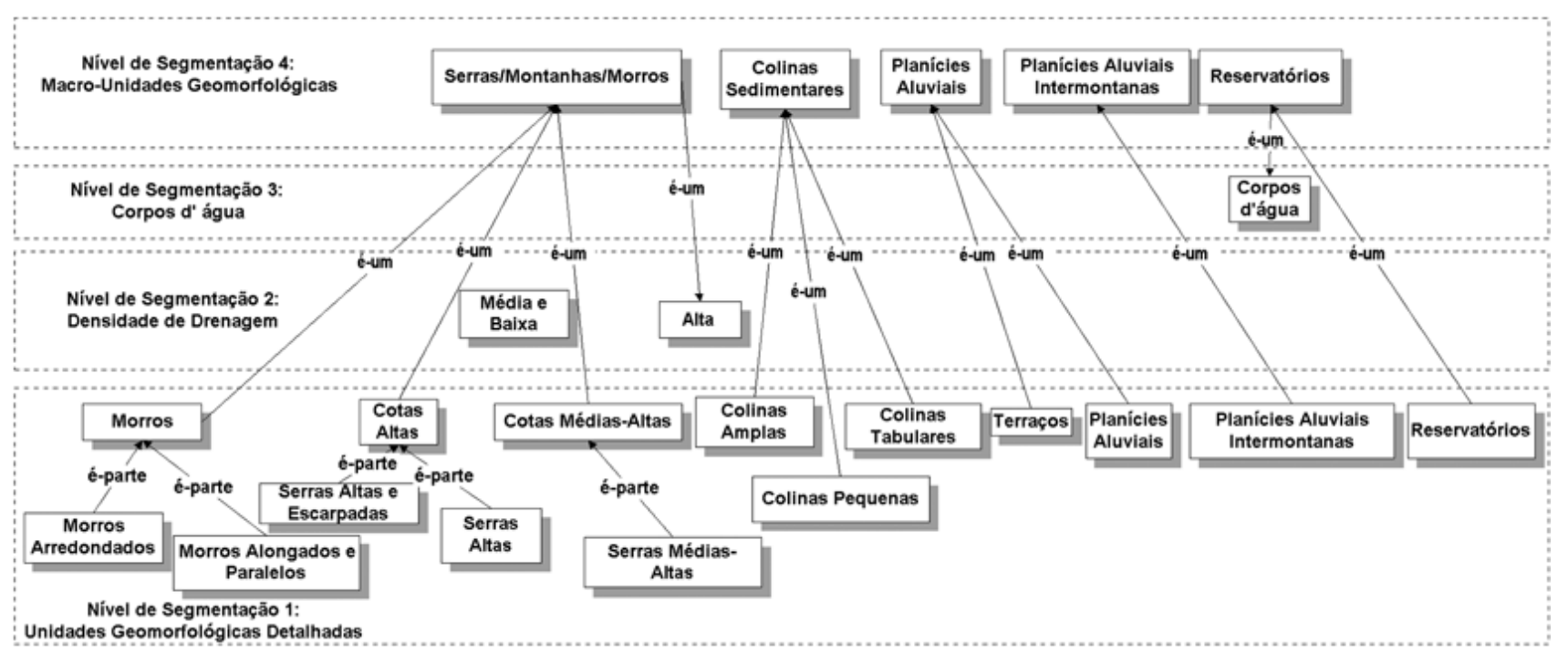

Figura 3 - Rede semântica hierárquica empregada na classificação das unidades geomorfológicas detalhadas. 
de um dado atributo, verificados nas vizinhanças dos objetos. Por exemplo, um objeto não classificado não está totalmente contido por objetos de uma dada classe e, desse modo, não pode ser classificado pelo primeiro algoritmo. Neste caso, podemos utilizar uma busca de todos os objetos não-classificados com valores extremos (máximo, por exemplo) de vizinhança com uma dada classe ("Colinas Sedimentares", por exemplo). Os objetos que atenderem a essa regra serão classificados como "Colinas Sedimentares".

A validação do mapa geomorfológico final foi realizada a partir de uma tabela de contingência, responsável pela comparação entre o mapa de referência e a classificação das unidades geomorfológicas detalhadas. Adicionalmente, avaliaram-se as incertezas do processo de classificação por meio do índice de estabilidade da classificação. Este índice calcula, para cada objeto, a diferença entre o maior e o segundo maior valor de pertinência. Quanto maior esta diferença, mais estável é a classificação.

RESULTADOS E DISCUSSÃO Anteriormente à validação, por meio de uma análise qualitativa do MDE, detectaram-se áreas sem dados (problemas na extração das paralaxes). Essas áreas são mostradas na figura 4 por círculos. Para a validação, foram calculadas as discrepâncias entre os valores altimétricos obtidos do MDE gerado e da altitude dos pontos GPS (MDE - Altitude GPS). Os resultados das estatísticas descritivas são apresentados na tabela 10. Adicionalmente, também foi aplicado o teste $t$ Student $(\alpha=10 \%)$ para se verificar a ocorrência ou não de tendência nas discrepâncias obtidas (Tab. 10).

No MDE gerado, foram detectadas áreas sem informação altimétrica, destacadas por círculos na figura 4 , que correspondem a corpos d'água e sombras das encostas. Como nestes alvos a variância entre os pixels é próxima a zero, a estéreo-correlação e a extração automática das paralaxes são prejudicadas, resul-
Tabela 10 - Resumo das estatísticas de validação da altimetria do MDE ASTER/Terra.

\begin{tabular}{l|c}
\hline $\mathrm{N}^{\mathrm{o}}$ de pontos GPS & 109 \\
\hline Erro Mínimo (m) & $-18,40$ \\
\hline Erro Máximo (m) & 30,60 \\
\hline Média (m) & 4,14 \\
\hline Desvio Padrão (m) & 8,40 \\
\hline Erro Médio Quadrático (m) & 9,38 \\
\hline & 5,146 \\
\hline$t_{\text {amostral }} \mid$ & 1,659 \\
\hline & \\
\hline$t_{(n-1,5 \%)}$ & \\
\hline
\end{tabular}

tando em áreas sem informação.

Por outro lado, os resultados da validação do MDE ASTER/Terra (Tab. 10) concordam com trabalhos na mesma linha de pesquisa (Oliveira \& Paradella 2008, Toutin 2008), com destaque para o erro médio quadrático (EMQ) de 9,38 m. Observa-se também que a hipótese nula do teste $t$-Student $\left(\left|t_{\text {amostral }}\right|<t_{(n-1,5 \%)}\right)$ foi rejeitada e que o MDE apresentou tendência positiva. Esse resultado é coerente, pois o MDE sofre a interferência da altura de diferentes tipos de cobertura da terra.

Conforme mencionado, dois níveis de segmentação foram destinados à classificação de unidades geomorfológicas. Nas figuras 5 e 6, são apresentadas, respectivamente, as classificações das macro-unidades geomorfológicas e das unidades geomorfológicas detalhadas. Na tabela 11, que apresenta a matriz de contingência, foram analisados os erros de comissão (linhas) e omissão (colunas) e obtidos os seguintes indicadores estatísticos: acurácia global e índice Kappa. Também foi realizada uma análise estatística descritiva dos re-

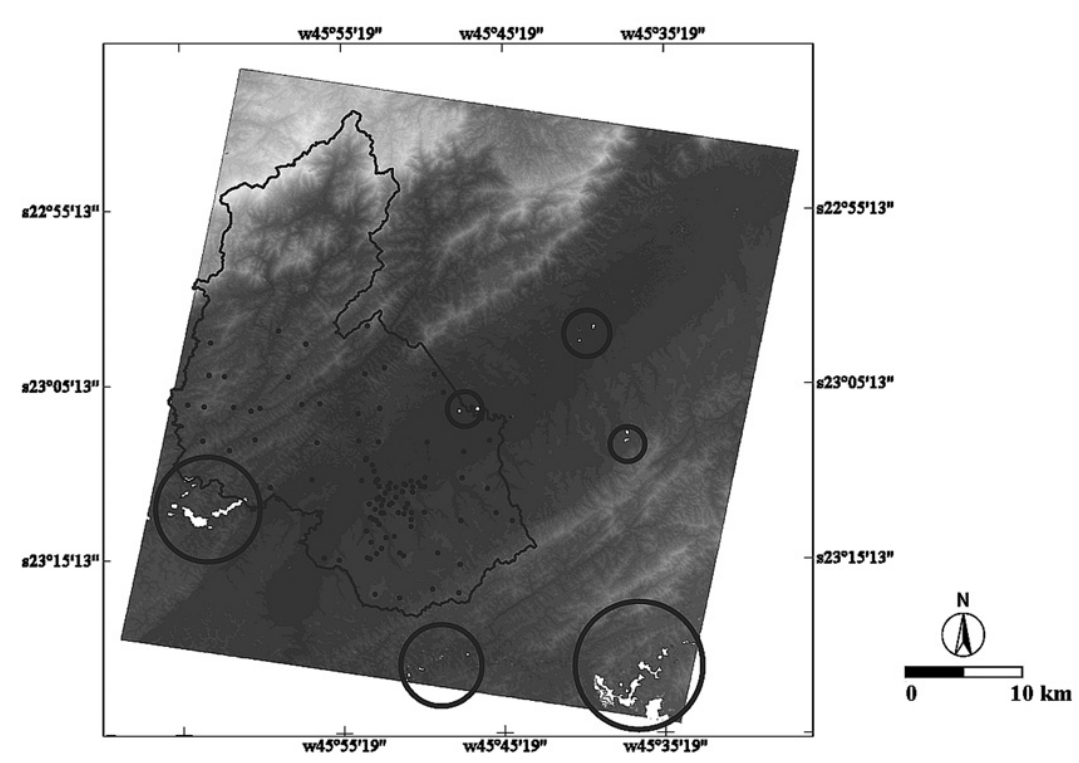

Figura 4 - MDE, pontos GPS (em preto) e ausência de dados (círculos em preto). 

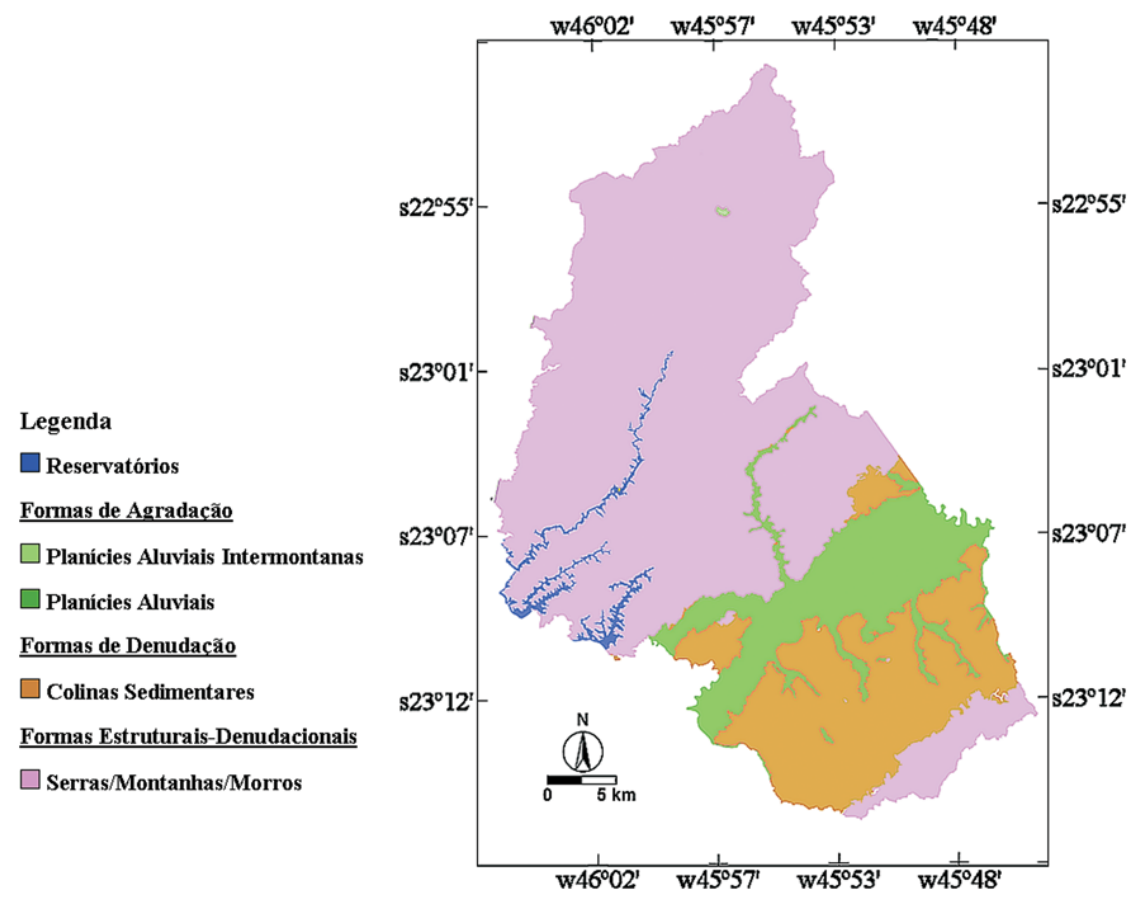

Figura 5 - Resultado da classificação semi-automatizada das macrounidades geomorfológicas.

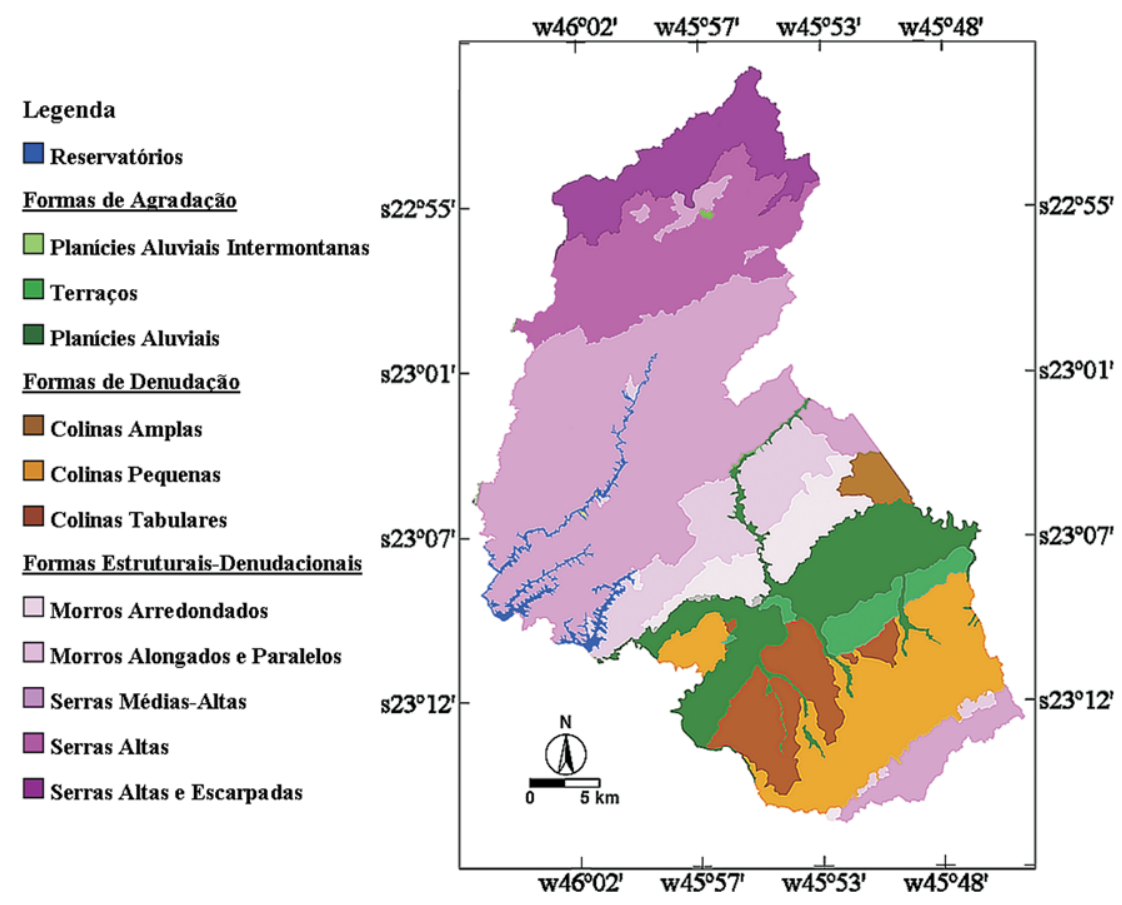

Figura 6 - Resultado da classificação semi-automatizada das unidades geomorfológicas detalhadas.

sultados fornecidos pelo índice de estabilidade da classificação (Tab. 12).

Na figura 6, referente à classificação das unidades geomorfológicas detalhadas, observa-se que a atividade tectônica Pré-Cambriana condicionou o arranjo e a distribuição espacial das formas de relevo da área de estudo. As formas de gênese estrutural-denudacional apresentam uma evidente compartimentação no sentido sudeste-noroeste, e as formas sedimentares Terciárias se concentram na porção sul-sudeste devido à inclinação norte-noroeste do hemi-graben, a qual condiciona o deslocamento do canal fluvial do rio Paraíba do Sul no sentido noroeste (Verdade \& Hungria 1966, Almeida 2000). Pela análise dos erros de comissão (linhas) e 
Tabela 11 - Matriz de contingência e resultados da acurácia global e do índice Kappa.

\begin{tabular}{|c|c|c|c|c|c|c|c|c|c|c|c|c|c|c|}
\hline \multirow{13}{*}{ 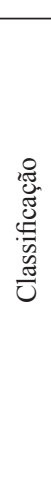 } & \multicolumn{12}{|c|}{ Mapa de Referência } & \multirow[b]{2}{*}{ Legenda: } & \multirow[b]{3}{*}{ Colino A mole } \\
\hline & & 1 & 2 & 3 & 4 & 5 & 6 & 7 & 8 & 9 & 10 & 11 & & \\
\hline & 1 & 4 & 0 & 0 & 0 & 0 & 0 & 0 & 0 & 0 & 0 & 0 & 1 & \\
\hline & 2 & 0 & 36 & 0 & 0 & 0 & 0 & 0 & 0 & 0 & 0 & 0 & 2 & Colinas Pequenas \\
\hline & 3 & 0 & 2 & 19 & 0 & 0 & 0 & 0 & 0 & 0 & 0 & 0 & 3 & Colinas Tabulares \\
\hline & 4 & 0 & 0 & 0 & 12 & 0 & 0 & 0 & 0 & 0 & 0 & 4 & 4 & Morros Arredondados \\
\hline & 5 & 0 & 0 & 0 & 0 & 19 & 0 & 0 & 0 & 0 & 0 & 10 & 5 & Morros Alongados e Paralelos \\
\hline & 6 & 0 & 0 & 0 & 0 & 0 & 75 & 0 & 0 & 0 & 0 & 0 & 6 & Planícies Aluviais \\
\hline & 7 & 0 & 2 & 0 & 0 & 0 & 7 & 15 & 0 & 0 & 0 & 0 & 7 & Terraços \\
\hline & 8 & 0 & 0 & 0 & 0 & 0 & 0 & 0 & 2 & 0 & 0 & 0 & 8 & Planícies Aluviais Intermontanas \\
\hline & 9 & 0 & 0 & 0 & 0 & 0 & 0 & 0 & 0 & 12 & 3 & 0 & 9 & Serras Altas e Escarpadas \\
\hline & 10 & 0 & 0 & 0 & 0 & 0 & 0 & 0 & 0 & 8 & 19 & 0 & 10 & Serras Altas \\
\hline & 11 & 0 & 0 & 0 & 0 & 7 & 0 & 0 & 0 & 1 & 5 & 83 & 11 & Serras Médias-Altas \\
\hline & & & & & 0,8 & & & & & & & & & \\
\hline & & $\mathrm{Ac}$ & Itacts & & $\mathrm{al}=$ &, 860 & & & & & & & & \\
\hline
\end{tabular}

omissão (colunas), obtidos da tabela 11 , verifica-se que a classe "Planícies Aluviais" apresentou confusão com a classe "Terraços". Isso se deve, principalmente, às características geomorfométricas similares (declividade e altimetria) entre ambas as classes. No caso das unidades com gênese estrutural-denudacional, erros significativos ocorreram entre as classes "Morros Arredondados" e "Serras Médias-Altas"; entre "Serras Alongadas e Paralelas" e "Serras Médias-Altas" e, também, entre as classes "Serras Altas Escarpadas" e "Serras Altas". Apesar de morfograficamente distintas, essas classes apresentam semelhanças morfométricas quando considerados determinados atributos, tais como altimetria.

Foram observados poucos erros entre classes de domínios morfogenéticos distintos (entre terrenos sedimentares quaternários e terrenos cristalinos précambrianos, por exemplo). Isso se deve à adequada separação desses domínios na etapa de classificação das macro-unidades geomorfológicas. Como o sistema Definiens permite a classificação multinível, regras considerando essa etapa inicial de classificação foram inseridas na rede semântica hierárquica final, de modo a minimizar a confusão na classificação das unidades geomorfológicas detalhadas.

A acurácia global calculada foi de 0,86 e apresentou uma pequena diferença em relação ao índice Kappa, que foi de 0,83 . Isto foi ocasionado pela baixa chance de concordância obtida dos valores marginais ou erros de comissão e omissão. Esses reduzidos erros também podem ser atribuídos à estratégia de classificação multinível e suas características, explicadas no parágrafo anterior. De acordo com a classificação de Landis \& Koch (1977), o índice Kappa obtido (Tab. 11) pode ser considerado de "forte concordância".

A análise descritiva dos resultados do índice de estabilidade da classificação (Tab. 12) mostra que as classes de origem estrutural-denudacional apresentaram os maiores valores médios, com um valor mínimo de 0,371 para "Serras Altas" e máximo de 0,717 para "Serras Médias-Altas". A despeito da alta estabilidade, estas classes foram as que apresentaram os maiores erros na tabela de contingência (Tab. 11). A alta estabilidade
Tabela 12 - Análise estatística descritiva obtida dos valores do índice de estabilidade da classificação.

\begin{tabular}{l|c|c|c|c|c}
\hline Classes & $\begin{array}{c}\text { Número de } \\
\text { Objetos }\end{array}$ & Média & $\begin{array}{c}\text { Desvio } \\
\text { Padrão }\end{array}$ & Mínimo & Máximo \\
\hline Colinas Amplas & 04 & 0,127 & 0,128 & 0,000 & 0,276 \\
\hline Colinas Pequenas & 36 & 0,164 & 0,150 & 0,000 & 0,310 \\
\hline Colinas Tabulares & 21 & 0,253 & 0,074 & 0,015 & 0,310 \\
\hline $\begin{array}{l}\text { Colinas Alongadas } \\
\text { e Paralelas }\end{array}$ & 29 & 0,498 & 0,084 & 0,285 & 0,593 \\
\hline $\begin{array}{l}\text { Morros } \\
\text { Arredondados }\end{array}$ & 16 & 0,586 & 0,261 & 0,163 & 0,994 \\
\hline Planícies Aluviais & 75 & 0,106 & 0,033 & 0,008 & 0,130 \\
\hline Terraços & 24 & 0,130 & 0,000 & 0,130 & 0,130 \\
\hline $\begin{array}{l}\text { Planícies Aluviais } \\
\text { Intermontanas }\end{array}$ & 2 & 1,000 & 0,000 & 1,000 & 1,000 \\
\hline Serras Altas & 27 & 0,371 & 0,340 & 0,000 & 0,870 \\
\hline $\begin{array}{l}\text { Serras Altas e } \\
\text { Escarpadas }\end{array}$ & 15 & 0,632 & 0,357 & 0,079 & 0,983 \\
\hline $\begin{array}{l}\text { Serras Médias- } \\
\text { Altas }\end{array}$ & 96 & 0,717 & 0,221 & 0,015 & 0,989 \\
\hline
\end{tabular}

pode ser atribuída aos atributos "média da altimetria" e "valores máximos de altimetria" (Tab. 9), os quais são muito peculiares em cada uma das classes mencionadas. Acredita-se que isto seja devido, principalmente, à estrutura de blocos falhados do hemi-gráben. Porém, apesar desta marcada compartimentação altimétrica, as classes de origem estrutural-denudacional têm maior quantidade de objetos devido à alta variabilidade espacial ocasionada pela intensa dissecação da rede de drenagem de padrão dendrítico. Isso pode ter possibilitado a predominância de erros de comissão e omissão nas classes de origem estrutural-denudacional.

Acredita-se que o oposto ocorreu com as formas de agradação e de denudação. Nestas, as similaridades entre os atributos (Tabs. 7 e 8) podem ter possibilitado os baixos valores médios do índice de estabilidade, com um valor mínimo de 0,106 para "Planícies Aluviais" e 0,253 para "Colinas Tabulares". No entanto, a maior homogeneidade e a baixa dissecação da rede de 
drenagem, presentes nessas unidades, possibilitaram a geração de objetos maiores e adequados para a separação estatística das classes de interesse.

CONCLUSÕES O objetivo deste trabalho foi desenvolver um método semi-automatizado de mapeamento geomorfológico, utilizando uma abordagem baseada em conhecimento especialista e variáveis derivadas de um MDE ASTER/Terra. Face aos resultados obtidos, são destacadas as principais conclusões:

Apesar da média resolução espacial das imagens ASTER/Terra (15 m), o MDE foi adequado para a identificação de feições de relevo sutis, tais como os terraços e a planície aluvial intermontana. $\mathrm{Na}$ área de estudo, os terraços apresentam uma diferença altimétrica mínima em relação à planície aluvial, de aproximadamente $10 \mathrm{~m}$. Aliada a essa capacidade de detalhamento, as imagens ASTER/Terra são de custo acessível, possibilitam a visão estereoscópica e, também, uma adequada integração entre dados multiespectrais e altimétricos. Essa integração elimina erros ocasionados pela incompatibilidade entre dados de diferentes fontes (MDEs, imagens multiespectrais etc.) e com diferentes resoluções espaciais. É importante destacar que, por se tratarem de dados gerados por um sensor óptico, a qualidade das imagens ASTER/ Terra (e de dados derivados) sofre a influência da cobertura de nuvens presente no momento da aquisição.

O algoritmo de segmentação multiresolução foi eficiente na delimitação das 11 unidades definidas na legenda. Isso se deve, principalmente, à capacidade desse algoritmo de gerar diversos níveis de segmentação com diferentes níveis de detalhamento ou escalas de generalização. Esse recurso permitiu a separação paulatina das unidades geomorfológicas, partindo das extensas unidades morfogenéticas (macro-unidades geomorfológicas) até o detalhamento das 11 unidades morfográficas da legenda definida (unidades geomorfológicas detalhadas).

A rede semântica hierárquica foi capaz de representar e reproduzir regras que consideraram aspectos topológicos, de contexto, morfométricos e texturais. Tais regras se basearam em conhecimento geomorfológico acerca da área de estudo e foram imprescindíveis na obtenção do alto índice de concordância Kappa.

Os resultados da rede semântica hierárquica sugerem que ela pode ser replicável para outras áreas de estudo com configurações morfológicas semelhantes, uma vez que o sistema permite o ajuste das funções e seus limiares, a fim de garantir a conformidade da rede à realidade em análise. Assim, o intérprete economiza esforço de modelagem e tempo de processamento computacional.

Outro desafio é a diminuição do tempo na seleção de atributos e determinação de suas respectivas funções nebulosas (em termos de formato e limiares). Neste sentido, devem-se priorizar rotinas e métodos que otimizem essas tarefas, explorando algoritmos de árvores de decisão, na seleção de atributos, bem como sistemas que combinam redes neurais artificiais e lógica nebulosa na definição automática das funções de pertinência.

Agradecimentos Agradecemos às instituições de fomento à pesquisa CAPES e CNPq; à FINEP/SEBRAE (Proc. 2799/06); aos dados GPS fornecidos por FUNCATE, INPE e IEAv, e também, ao Dr. Carlos Roberto de Souza Filho (IG-UNICAMP), pela cessão das imagens ASTER/Terra.

\section{Referências}

Abrams M., Hook S., Ramachandran B. 1999. ASTER user handbook (Version 2). Jet Propulsion Laboratory - EROS Data Center, Sioux Falls, South Dakota.Disponível em:

http://asterweb.jpl.nasa.gov/content/03_data/04_Documents/aster_user_guide_v2.pdf, Acessado em 01 Fev 2007.

Almeida F.F.M. 2000. The origin and evolution of the South American Platform. Earth-Science Reviews, 50:77-111.

Almeida F.F.M. \& Carneiro C.D. 1998. Origem e evolução da Serra do Mar. Revista Brasileira de Geociências, 28:135-150.

Asselen S. \& Seijmonsbergen A.C. 2006. Expert-driven semi-automated geomorphological mapping for a mountainous area using a laser DTM. Geomorphology, 78:309-320.

Baatz M. \& Schäpe A. 2000. Multiresolution segmentation - an optimization approach for high quality multi-scale image segmentation. In: Strobl J., Blaschke T., Griesebner G. (eds.) Angewandte Geographische InformationsVerarbeitung XII. Wichmann Verlag, p. 12-23.

Benz U.C., Hofmann P., Willhauck G., Lingenfelder I., Heynen M. 2004. Multi-resolution, object-oriented fuzzy analysis of remote sensing data for GIS-ready in- formation. ISPRS Journal of Photogrammetry \& Remote Sensing, 58:239-258.

Camargo F.F. 2008. Análise orientada a objeto aplicada ao mapeamento de unidades geomorfológicas a partir de dados ASTER/Terra. Dissertação de Mestrado, Instituto Nacional de Pesquisas Espaciais, São José dos Campos (SP)/Brasil, 171p. Disponível em: http://urlib.net/sid. inpe.br/mtc-m17@80/2008/03.17.19.50, Acessado em 25 Mai 2008.

Clausi D.A. 2002. An analysis of co-occurrence texture statistics as a function of grey level quantization. Canadian Journal of Remote Sensing, 28:45-62.

Definiens 2006. Definiens professional 5: reference book. Definiens (The Imaging Intelligence Company), Munich, $122 \mathrm{p}$.

DEPARTAMENTO NACIONAL DE PRODUÇÃO MINERAL (DNPM). 1983. Folhas SF 23/24 (Rio de Janeiro/ Vitória): geologia, geomorfologia, pedologia, vegetação e uso potencial da terra. DNPM, v. 32, 775 p.

Ehlers M. \& Welch R. 1987. Stereocorrelation of Landsat TM images. Photogrammetric Engineering and Remote Sensing, 53:1231-1237.

Florenzano T.G. \& Csordas S.M. 1993. Mapa geomorfoló- 
gico da região do Vale do Paraíba e Litoral Norte do Estado de São Paulo. INPE, São José dos Campos (SP), escala 1:250 000.

Giles P.T. \& Franklin S.E. 1998. An automated approach to the classification of the slope units using digital data. Geomorphology, 21:251-264.

INSTITUTO DE PESQUISAS TECNOLÓGICAS (IPT) 1981. Mapa geomorfológico do Estado de São Paulo. São Paulo (SP), IPT, escala 1:1 000000.

Klimaszewski M. 1982. Detailed geomorphological maps. ITC Journal, 3:265-271.

Kressler F.P. \& Steinnocher K. 2006. Image data and LIDAR - An ideal combination matched by object-oriented analysis. In: International Conference on Object-based Image Analysis (OBIA 2006), 1, Viena, Austria, Proceedings of the First International Conference on Object-based Image Analysis, Viena: ISPRS. Disponível em:http://www. commission4.isprs.org/obia06/Papers/08_Automated\%20classification\%20Lidar/OBIA2006_Kressler Steinnocher.pdf. Acessado em 18 Jan 2008.

Landis J. \& Koch G. 1977. The measurement of observer agreement for categorical data. Biometrics, 33:159-174.

Lohani B. \& Mason D.C. 2001. Application of airborne scanning laser altimetry to the study of tidal channel geomorphology. ISPRS Journal of Photogrammetry and Remote Sensing, 56:100-120.

McBratney A.B. \& Odeh I.O.A. 1997. Application of fuzzy sets in soil science: fuzzy logic, fuzzy measurements and fuzzy decisions. Geoderma, 77:85-113.

Miliaresis G.C. \& Argialas D.P. 2002. Quantitative representation of mountain objects extracted from the global digital elevation model (GTOPO30). International Journal of Remote Sensing, 23:949-964.

Moore T. 2000. Geospatial expert systems. In: Openshaw S. \& Abrahart R.J. (eds.) Geocomputation. London, Taylor \& Francis, p.125-159.

Moore A.B., Morris K.P., Blackwell G.K., Jones A.R., Sims P.C. 2003. Using geomorphological rules to classify photogrammetrically-derived digital elevation models. International Journal of Remote Sensing, 24:2613-2626.

Mueller M., Segl K., Kaufmann H. 2004. Edge- and regionbased segmentation technique for the extraction of large, man-made objects in high-resolution satellite imagery. Pattern Recognition Letters, 37:1619-1628.

Muñoz X., Freixenet J., Cufi X., Marti J. 2003. Strategies for image segmentation combining region and boundary information. Pattern Recognition Letters, 24:375-392.

Oliveira C.G. \& Paradella W.R. 2008. An assessment of the altimetric information derived from spaceborne SAR (RADARSAT-1, SRTM3) and optical (ASTER) data for cartographic application in the Amazon region. Sensors, 8:3819-3829.

PCI Geomatics 2006. Geomatica v. 10.0.3 user guide. Ontário, Canada, Richmond Hill.

Ross J.L.S. \& Moroz I.C. 1997. Mapa geomorfológico do Estado de São Paulo. São Paulo, HUMANITAS/IPT/ FAPESP, escala 1:500 000.

Rumbaugh J., Blaha M., Premerlani W., Eddy F., Lorensen W. 1991. Object-oriented modeling and design. Prentice Hall, Englewood Cliffs, NJ, 500 p.
Shary P.A. 2007. Local morphometric variables. In: Peter Shary's Personal Website. Disponível em: http:// www.giseco.info/pb/wp_d4052550/wp_d4052550. html?0.7718744701805855, Acessado em 17 Mar 2008.

Schiewe J., Tufte L., Ehlers M. 2001. Potential and problems of multi-scale segmentation methods in remote sensing. GIS - Zeitschrift für Geoinformationssysteme, 6:34-39.

Schneevoigt N.J., van der Linden S., Thamm H.-P., Schrott L. 2008. Detecting Alpine landforms from remotely sensed imagery: A pilot study in the Bavarian Alps. Geomorphology, 93:104-119.

Smith M. J., Rose J., Booth S. 2006. Geomorphological mapping of glacial landforms from remotely sensed data: An evaluation of the principal data sources and an assessment of their quality. Geomorphology, 76:148-165.

Soulakellis N.A., Novak I.D., Zouros N., Lowman P., Yates J. 2006. Fusing Landsat-5/TM imagery and shaded relief maps in tectonic and geomorphic mapping: Lesvos Island, Greece. Photogrammetric Engineering \& Remote Sensing, 72:693-700.

Tönjes R., Growe S., Bückner J., Liedtke C.-E. 1999. Knownledge-based interpretation of remote sensing images using semantic nets. Photogrammetric Engineering \& Remote Sensing, 65:811-821.

Toutin T. 2002. Three-dimensional topographic mapping with ASTER stereo data in rugged topography. IEEE Transactions on Geoscience and Remote Sensing, 40:22412247.

Toutin T. 2004a. Review article: Geometric processing of remote sensing images: models, algorithms and methods. Intern. Journal of Remote Sensing, 25:1893-1924.

Toutin T. 2004b. Comparison of stereo-extracted DTM from different high-resolution sensors: SPOT-5, EROS-A, IKONOS-II, and QuickBird. IEEE Transactions on Geoscience and Remote Sensing, 42:2121-2129.

Toutin T. 2006. Generation of DSMs from SPOT-5 in-track HRS and across-track HRG stereo data using spatiotriangulation and autocalibration. ISPRS Journal of Photogrammetry and Remote Sensing, 60:170-181.

Toutin T. 2008. ASTER DEMs for geomatic and geoscientific applications: a review. International Journal of Remote Sensing, 7:1855-1875.

Toutin T. \& Gray L. 2000. State-of-the-art of elevation extraction from satellite SAR data. ISPRS Journal of Photogrammetry \& Remote Sensing, 55:13-33.

Verdade F.C. \& Hungria L.S. 1966. Estudo genético de bacia orgânica do Vale do Paraíba. Bragantia, 25:189-202.

Verstappen H.Th. 1972. Interpretation of aerial photographs. In: Demek J. (ed.) Manual of detailed geomorphological mapping. Academy of Sciences, Praga, p. 40-45.

Verstappen H.T. \& van Zuidam R.A. 1991. The ITC system of geomorphologic survey: a basis for the evaluation of natural resources and hazards. ITC,Enschede, v.10, 89p.

van Zuidam R.A. 1986. Aerial photo-interpretation in terrain analysis and geomorphologic mapping. Smits Publishers, Enschede, 442 p.

Manuscrito ID 13432

Submetido em 06 de fevereiro de 2009 Aceito em 21 de junho de 2009 